www.jmscr.igmpublication.org Impact Factor 5.244

Index Copernicus Value: 83.27

ISSN (e)-2347-176x ISSN (p) 2455-0450

crossref DOI: _https://dx.doi.org/10.18535/jmscr/v4i11.10

Journal Of Medical Science And Clinical Research

\title{
Pregnancy Complicated By Odontogenic Facial Space Infection; A Study
}

\author{
Authors \\ Dr Tanveer Akhter ${ }^{1}$, Dr Usma Jabeen ${ }^{2}$, Dr Mohammed Israr Ul Khaliq ${ }^{3}$, \\ Dr Mohd Anwar ${ }^{4}$ \\ ${ }^{1}$ Consultant Gynaecologist in JKNHM, Email: drisrarch@gmail.com \\ ${ }^{2}$ Post Graduate Scholar, Department of Anesthesiology and Critical Care, SKIMS Soura \\ Email:drusmach@gmail.com \\ ${ }^{3}$ Post Graduate Scholar, Dept of Oral and Maxillofacial Surgery, Govt. Dental College \& Hospital, Srinagar \\ Email:drisrarch@gmail.com \\ ${ }^{4}$ Resident SKIMS MC Srinagar, Email: drisrarch@gmail.com
}

\begin{abstract}
Introduction: Odontogenic neck space infections represent a severe disease with possible life-threatening complications. Therapy of severe neck infections is even more crucial during pregnancy because of the possible life-threatening situation for both the mother and the foetus.

Aim: The study was done to describes the course of a deep neck space infection in pregnant patients, commencing with typical symptoms of localized odontogenic infection and ending in a critical, life-threatening condition for the patient.

Study Design /Material \& Methods: The 14 pregnant females were randomly selected to describes the course of a deep neck space infection in pregnant patients, commencing with typical symptoms of localized odontogenic infection and ending in a critical, life-threatening condition for the patient. Implications for dental and medical treatment during pregnancy, especially regarding odontogenic infections, are presented and discussed with findings in the international literature.

Conclusion: Infections are common in pregnancy due to hormonal changes and altered immunological activity aggravating response to plaque accumulation and caries resulting in serious life threatening condition, like Ludwigs Angina. So Every mother should be closely examined by her dentist before and during pregnancy to avoid any deleterious complications for herself and the foetus.

Keywords: Pregnancy, pregnant female, odontogenic facial space infections, Abscess, deep neck infection.
\end{abstract}

\section{Introduction}

Ludwig's Angina is a rare consequence of odontogenic infection that can result in severe upper airway obstruction and potentially death.In the early stages of odontogenic space infection , the patient's symptoms are often underestimated, leading to errors in diagnosis and treatment of the disease or a delay in the correct therapy. ${ }^{[1-2]}$ Pregnancy is associated with many physiological and hormonal changes, providing the oral and maxillofacial surgeon with many challenges. If proper precautions are not taken, these alterations can lead to serious complications. ${ }^{[3]}$ Infection from the original focus can spread along the tissue spaces and lead to facial cellulitis involving deeper facial spaces. These spaces are bounded by muscles, bones and actual facial layers. These spaces communicate with one another and 
therefore, allow the spread of infection beyond single space. Treatment of pregnant patients involve dealing the lives of two individuals (the mother and unborn fetus), certain principles have been developed which must be considered by an oral and maxillofacial surgeon while handling such patients, but unfortunately in farflung areas there is lack of modern health care facilities and many a times such pregnant females are treated with leaches for facial space infection(Fig 1 and 2). So management plan should be such that it should maximize benefit to the mother and minimizing the risk to the developing fetus. ${ }^{[4]}$ It is necessary for an oral and maxillofacial surgeon to consult the patients obstetrician or medical specialist in a clinical situation providing a framework for the surgeon in making medical decision for the pregnant patient. ${ }^{[5]}$ In pregnancy there are changes in the respiratory physiology due to increased oxygen demands of the maternalfetal system. There is an increase in tidal volume and minute ventilation rate caused by superior displacement of the diaphragm (upto 3-4 cm) resulting in dyspnea. ${ }^{[6-7]} \mathrm{Up}$ to $50 \%$ of patients exhibit this clinical sign by the middle of the second trimester, and up to $75 \%$ exhibit it by the middle of the third trimester. ${ }^{[8]}$

Hyperventilation is also a common finding in the pregnant patient and is present in approximately $40 \%$ of patients late in pregnancy. ${ }^{9}$ Life threatening odontogenic infections as ludwigs angina can aggrevate these respiratory changes occurring in pregnancy, as it is associated with severe airway compromise. Therefore early incision and drainage of odontogenic infections are indicated, as is appropriate use of antibiotics with primary concern should be given to airway security. ${ }^{[10-11]}$

Patients with extreme limitation of mouth opening, fever of above $102 \mathrm{~F}$ and dysphagia were hospitalized and managed under local/ general anesthesia depending upon the condition of the patient, by incision and drainage with extraction of the causative tooth. Incision was carried out using blade no 15 and pus drained facilitated by corrugated rubber drain. The rubber drain was removed till stoppage of the pus drainage. Patients were given intravenous antibiotics and fluids during their stay at the hospital.

\section{Results}

A total of 14 pregnant female patients were recruited in the study. The age range was from 18 to 30 years, mean age of 24.78 years $\mathrm{SD} \pm 5.043$ (Table 1). Seven (50\%) females presented with odontogenic infections in their last trimester and six patients( $42.85 \%$ ) were in their late second trimester. The remaining one patient $(7 \%)$ was in their first trimester of pregnancy. (Table 1). All of these patients presented clinically with limited mouth opening with fascial swelling and dysphagia. Tenderness and warmth was observed on palpation extraorally, and pus discharge on aspiration of the involved space. All patients had systemic signs of infection including fever, dehydration and lethargy. On laboratory investigations a complete blood count revealed increased leukocyte count.

Table 1: Age Distribution in Pregnant Patients with Odontogenic Infection

\begin{tabular}{|l|c|c|}
\hline $\begin{array}{l}\text { Trimester Of } \\
\text { Patient }\end{array}$ & $\begin{array}{c}\text { Number Of } \\
\text { Patients }\end{array}$ & $\begin{array}{c}\text { Percentage Of } \\
\text { Patients }\end{array}$ \\
\hline Last trimester & 7 & $50 \%$ \\
\hline Second trimester & 6 & 42.85 \\
\hline First trimester & 1 & 7.1 \\
\hline Total patients & 14 & $100 \%$ \\
\hline
\end{tabular}
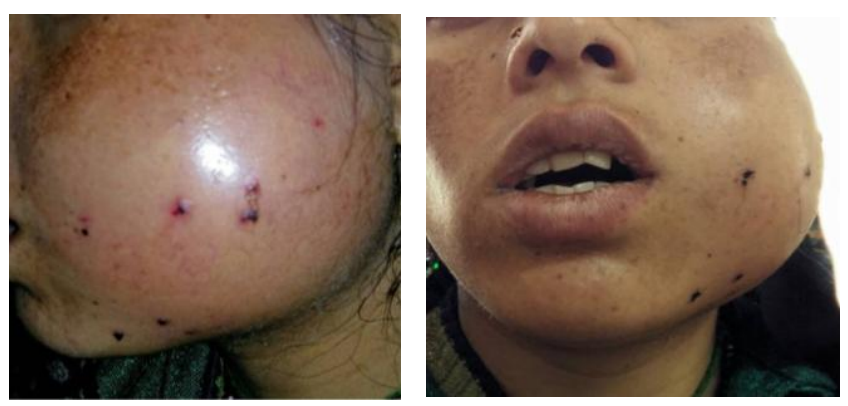

Fig. 1 and 2: Severe facial space infection treated with application of leeaches on skin by villageman

\section{Discussion}

Odontogenic infection is the most prevalent disease worldwide and is the main reason for seeking dental care. Odontogenic infections are known to be the main cause of facial space 
infections. Despite knowledge of these infectious diseases, treatment remains a challenge for every maxillofacial surgeon. The possible compromise of oral health during pregnancy is well known, however severe odontogenic infections are rarely considered in the literature.

The commonest odontogenic infections are periapical abscess, pericoronitis and periodontal abscess ${ }^{[12-13]}$. Facial spaces are potential spaces divided into primary and secondary on the basis of direct and indirect involvement from the original focus. Common complaints associated with these infections are swelling, pain, pus discharge, limitation of mouth opening, dysphagia and fever. ${ }^{[14]}$ The prevalence of odontogenic infection involving primary fascial spaces in descending order is submandibualr (28.2\%), submental $(14.8 \%)$, buccal $(12 \%)$ and sublingual $(11.3 \%) .{ }^{[15]}$ In the present study the also most commonly invoved space is submandibular (28\%), bilateral submandibular sublingual and submental in combination (32.1\%), submandibular and submental in combination (14.2\%), buccal (7.1\%), masseteric $(7.1 \%)$ and isolated submental space (3.5\%). Odontogenic infections can lead to serious complications if early treatment is not provided, including upper airway obstruction, descending mediastenitis, jugular vein thrombosis, septic shock, acute renal failure, disseminated intravascular coagulation, carotid artery pseudo aneurysm and pericardial effusion. ${ }^{[16]}$ Each year it is estimated that about 50,000 women undergo anesthesia and a surgical intervention at some time during gestation for indications unrelated to the pregnancy. ${ }^{[17]}$ Pregnancy is accompanied by many physiological changes which place the mother at a higher risk of infection or having grave consequences once infected. First, the immune response is greatly diminished during pregnancy, thus resulting in potential faster progression of an infection. In addition, there is decreased neutrophil chemotaxis, cell mediated immunity, and natural killer cell activity and also there is decrease in oxygen reserve of gravid patient. [18] Concerning the use of local anaesthetics, lidocaine, prilocaine and articaine are the substances of choice without any known risk for teratogenic or toxic effects on the foetus. Consequently, the dental care of decayed teeth, apical periodontitis or even localized odontogenic abscesses is safely feasible. Pregnancy related hormonal changes affects the human body it also has some affect on the oral cavity affecting the gingival tissues. They become much more sensitive and suscepitable to irritation from soft plaque. The plaque accumulates, becomes hard calculus deposits on the teeth, and harbors bacteria in large numbers resulting in a constant, low grade intraoral infection. An exaggerated local inflammatory response can then begin and may result in erythematous and edematous swelling of the gingival between the teeth, also known as pregnancy gingivitis. Approximately $70 \%$ of pregnant women have this condition, even with routine oral care. ${ }^{[3]}$ These changes are aggravated during the last trimester and second trimester of pregnancy. As in the present study patients with increased number of odontogenic infections were in their last trimester (50\%), second trimester $(28.5 \%)$ and $(21.4 \%)$ in their first trimester. Maternal infections are caused especially by gram negative anaerobic bacteria, such as those leading to Ludwig's angina, have been demonstrated to cause physiologic imbalance through inflammatory cytokine production, sometimes resulting in preterm labour, preterm premature rupture membranes, and low birth weight. ${ }^{[19]}$

Because a pregnant patient has increased demands on her organs, there is increased potential for poor oxygenation. On the other hand, poor oxygenation is compromising to the fetus. An infection in itself can at times infect the placenta, uterus, and possibly the fetus, causing fetal septicemia. Treatments such as prolonged intubation and certain intravenous medications can also harm the fetus. ${ }^{[20]} 25 \%$ of pregnant patients develop moderate hypoxemia and some develop an abnormal alveolararterial oxygen gradient when placed in the supine position. ${ }^{[3]}$ Ventilation patterns and patient position must be adjusted for the pregnant patient so as to avoid hypoxemia. Regular routine dental visits should be planned for 
pregnant patients during early stages of pregnancy in order to identify the problem as early as possible and avoid serious complications. The most, appropriate time for dental treatment is second trimester, which is considered as the safe period ${ }^{[3]}$. In general management of a pregnant patient should include referral to the patients obstetrician before providing treatment ${ }^{[4]}$. Due to the increased abdominopelvic mass in pregnancy, there is compression of the inferior vena cava when the patient is placed in supine position resulting in supine hypotension syndrome. To prevent or alleviate supine hypotension, the pregnant patient should be rolled to the left side by $5 U$ to $15 U$ (a position in which the right hip is elevated 10-12 cm) which can be accomplished by inserting a wedge or pillow under the right hip. ${ }^{[21]}$ Ventilation patterns and patient position must be adjusted for the pregnant patient so as to avoid hypoxemia ${ }^{[3]}$. For the pregnant patient with frequent or excessive vomiting, morning appointments should not be scheduled. ${ }^{[6]}$ Given the increased frequency of urination normally seen in the pregnant patient, patients should be asked to void before starting treatment. Asymptomatic bacteriuria in the pregnant patient can progress to urinary tract infection and eventually pyelonephritis if untreated. ${ }^{[22]}$ Management of mild infections should be managed via incision/ drainage under local anesthetic with subsequent antibiotic coverage. It is essential to aggressively treat the gravid patient to minimize the risk of infection spreading to the facial spaces. Facial space infection should be handled in a standard fashion: airway assessment (if any doubt, intubate), imaging (computed tomography scan), and to the operating room for adequate incision and drainage. Postoperatively, if the patient is unable to maintain oral intake, parenteral nutritional support must be instituted. More severe infections should be managed in the operating room under general anesthesia with intravenous antibiotics and incision and drainage. Other issues with the gravid patient who is hospitalized for an extended period of time include avoiding bladder catheterization to minimize the risk of urinary tract infections and the use of subcutaneous heparin. ${ }^{[3]}$

The importance of an appropriate or more aggressive treatment of deep neck space infections has already been emphasized by several authors. ${ }^{[23]}$ Odontogenic infections can lead to serious consequences in pregnancy, as due to socioeconomic status and cultural issues in this part of the world, people have reservations in taking pregnant females to dentists. As pregnant patients are a challenge to treat because we are dealing two lives the mother and the fetus, management plan should be such that it provides maximum benefit to the mother and minimize risks to the fetus. Dental problems should be recognized earlier before it leads to grave outcomes.

\section{Conclusions}

The diagnosis of odontogenic infections is usually obvious. If not, a radiograph and a CT scan is performed. Mandibular last molars are the most commonly involved tooth in odontogenic infections in last trimester of pregnancy. We conclude that as mandibular last molar has the most unusual pattern of eruption and many patients had experienced percoronitis earlier, have an aggravated response to local inflammation in pregnancy resulting in fascial space infections. Infections are common in pregnancy due to hormonal changes and altered immunological activity aggravating response to plaque accumulation and caries resulting in serious life threatening condition, like Ludwigs Angina. So Every mother should be closely examined by her dentist before and during pregnancy to avoid any deleterious complications for herself and the foetus.

\section{References}

1. B. F. Marple, "Ludwig angina: a review of current airway management," Archives of Otolaryngology, vol. 125, no. 5, pp. 596600, 1999.

2. Smyth AG. Management of orofascial infections. In: Booth PW, Schendel SA, 
Hausamen JE. Maxillofacial Surgery. 2nd ed. Philadelphia: Elsevier publishers 2007; 1550-71.

3. Turner M, Aziz SR. Management of the Pregnant Oral and Maxillofacial Surgery Patient. J Oral Maxillofac Surg. 2002; 60: 1479-88.

4. Flynn RT, Susarla SM. Oral and maxillofacial surgery for pregnant patients. J Oral M.axillofac Surg. 2007; 19: 207-21.

5. Flynn TR. Complex odontogenic infections. In: Hupp JR, 111 EE, Tucker MR. Contemporary Oral and Maxillofacial Surgery. 5th ed. India: Elsevier publishers 2009; 317-36.

6. Suresh L, Radfar L. Pregnancy and lactation. J Oral Surg Oral Med Oral Pathol Oral Radiol Endod 2004; 97(6): 672-82.

7. McAuliffe F, Kametas N, Costello J, et al. Respiratory function in singleton and twin pregnancy. BJOG 2002; 109: 765-9.

8. Garcia-Rio F, Pino JM, Gomez L, et al. Regulation of breathing and perception of dyspnea in healthy pregnant women. Chest 1996; 110: 446-53.

9. Skatrud JB, Dempsey JA, Kaiser DG. Ventilatory response to medroxyprogesterone acetate in normal subjects. J Appl Physiol Respir Environ Exerc Physiol 1978; 44: 393-44.

10. Flynn TR, Shanti RM, Levy M, et al. Severe odontogenic infections: I. Prospective report. J Oral Maxillofac Surg 2006; 64:1093-103.

11. Lawrenz D, Whitley B, Helfrick J. Considerations in the management of maxillofacial infections in the pregnant patient. $\mathrm{J}$ Oral Maxillofac Surg 1996; 54: 474-85.

12. Piriz RL, Angulair L, Gimenez MJ. Management of odontogenic infection of pulpal and periodontal origin. Med Oral Patol Oral Cir Bucal 2007; 12: 154-9.

13. Neal D. Futran MD, DMD Peterson's Principles of Oral and Maxillo Facial
Surgery. 2nd edition by Michael Miloro, B.C. Decker, Inc., Hamilton, 2004, 1500

14. Rahman ZA, Hamimah H, Bunyarit SS. Clinical patterns of orofacial infections. Annal Dent Univ Malaya 2005; 12: 18-23.

15. Rega AJ, Aziz SR, Ziccardi VB. Microbiology and antibiotic sensitivity of head and neck space Infections of odontogenic origin. J Oral Maxillofac Surg 2006; 64: 1377-80.

16. Lee JK, Kim HD, Lim SC. Predisposing factors of complicated deep neck infection: An analysis of 158 cases. Younsei Med J 2007; 48: 55-62.

17. Aroesty JH, Lanza JT, Lucente FE. Otolaryngology and pregnancy difficult management decisions. J Otolaryngol Head and Neck Surg 1993;109(6): 1061-9.

18. Silver RM, Peltier MR, Branch DW. The immunology of pregnancy. In: Creasy RK, Resnik R, eds. Maternal-Fetal Medicine: Principles and Practice. Philadelphia, Pa:W. B. Saunders; 2004:89-109.

19. Scannapieco FA, Bush RB, Paju S. Periodontal disease as a risk factor for adverse pregnancy outcomes. A systematic review. Annals of Periodontology. 2003; 8: 70-78.

20. Moore PA. Selecting drugs for the pregnant dental patient. Journal of the American Dental Association. 1998; 129(9): 1281-6.

21. Duvekot JJ, Peeters LL. Maternal cardiovascular hemodynamic adaptation to pregnancy. Obstet Gynecol Surv 1994; 49(Suppl): S1-14.

22. Diokno AC, Compton A, Seski J. Urologic evaluation of urinary tract infection in pregnancy. J Reprod Med 1986; 31: 23-6.

23. Bottin R, Marioni G, Rinaldi R, Boninsegna M, Salvadori L, Staffieri A. Deep neck infection: a present-day complication. A retrospective review of 83 cases (1998-2001). Eur Arch Otorhinolaryngol 2003;260:576-579. 